\title{
Development of an exhaust gas recirculation system for diesel engines
}

\author{
Igor Ivanov, ${ }^{1, *}$ \\ ${ }^{1}$ Don State Technical University, Gagarin sq., 1, Rostov-on-Don, 344003, Russia
}

\begin{abstract}
This paper presents the author's method of developing an original solution to improve the efficiency of the exhaust gas recirculation system for diesel engines based on the TRIZ-FSA system with obtaining a patent for the method and device.
\end{abstract}

\section{Introduction}

In connection with the tightening of the requirements for exhaust gases from diesel engines, a large amount of research is being carried out to develop various methods for their reduction. To solve this problem, work is being carried out in the following directions: application of the exhaust gas recirculation system [1-3]; - adjusting the fuel supply system; -Changes in the process of air supply [4,5], changes in the composition of the fuel [6].

Among these works, the most developed process of mass introduction into automobile engines is the process of exhaust gas recirculation, which has been implemented on many models of Russian and foreign production. Moreover, in imported cars, this process was included in the electronic system for automating the engine work operation and, if properly adjusted, ensured an effective reduction in harmful emissions.

In terms of Russia, these systems work poorly and it is rather difficult to turn them off, therefore it is advisable to develop an upgrade of this system so that it can work effectively under various operating conditions.

\section{Urgency}

The existing exhaust gas recirculation (EGR) system for diesel engines reduces nitrogen oxides NOX in the exhaust gases, but at the same time, microparticles of soot during the recirculation process enter the working cavity of the engine cylinder, which helps to reduce engine life. In addition, in the USA and Europe, this system reliably works for 100 thousand $\mathrm{km}$ of run, and in our conditions, due to the lower fuel quality, 50-70 thousand $\mathrm{km}$, and if the system malfunctions, fuel consumption increases and the engine's service life decreases. ... Therefore, it is necessary to develop a more efficient recirculation system for operating in various operating conditions.

\footnotetext{
*Corresponding author: igoriv740@yandex.ru
} 


\section{Formulation of the problem}

Since the existing exhaust gas recirculation (EGR) system for diesel engines reduces the NOX content in the exhaust gases [7-12], but at the same time microparticles of soot entering the working cavity contribute to a decrease in the engine life, it is necessary to create such a system in which a synergistic effect of simultaneous reduction all harmful components and fuel consumption.

\section{The theoretical part}

Analysis of analogues.

On the basis of the working process analysis of the exhaust gas recirculation (EGR) system, which is used in domestic and foreign engines, first of all it is necessary to ensure the recirculation process so that soot microparticles do not enter the combustion chamber, and secondly, to increase the efficiency of the recirculation process.

In addition, on the basis of the study of the recirculation process influence on fuel consumption, it was found that this process helps to reduce fuel consumption at partial loads, and increases at maximum power. Therefore, it is necessary to provide controlled recirculation depending on the engine power.

Usage of TIPS elements (theory of inventive problem solving) to solve a problem $[13,14]$.

For solving, we will compose technical contradictions (TC):

TC-1. In order to reduce NOX in the exhaust gases, it is necessary to supply part of the exhaust gases to the suction system of the engine, but at the same time, micro-soot particles entering the working cavity contribute to a decrease the engine's service life.

TC-2 In order to prevent getting soot microparticles into the suction system of the engine, it is necessary to prevent their content in the flow of gases supplied to the suction system during recirculation, but in the exhaust stroke all components of the exhaust gases are in a mixed state.

We will take TC-2 as a basis, since it corresponds to the formulated goal.

To solve this contradiction, it was decided to whirl the exhaust gas flow and select for recirculation from the middle part of the flow, where the lighter components are concentrated. In addition, to provide a regulated recirculation system and reduce fuel consumption by supplying additional air through the recirculation system.

To solve this problem, we will use the principles of TIPS.

Resources for recirculation regulation must be taken from the system itself.

It is advisable to use the internal force action of the system as the X-element [1].

The analysis shows that if a whirling effect is created in the exhaust system, then the vacuum in the central part of the whirl can be used as the X-element. At the same time, if we connect the vacuum part of the whirl with the atmosphere, we get an adjustable air suction, which will change depending on the power and speed of the vehicle.

The system developed by the author in su-field form [1] is shown in Fig. 1. 


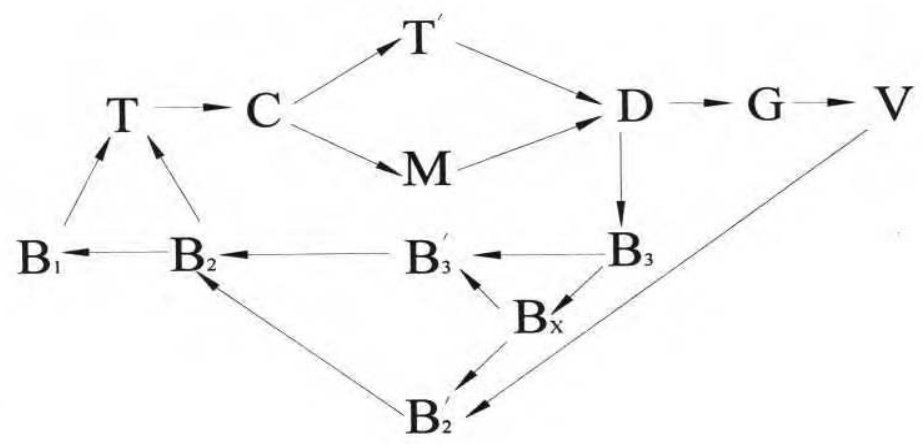

Fig.1. Su-field form of a self-regulating recirculation system with negative inverse connection.

B1 - fuel; B2 - air; T is the thermal field generated by compressing air in the cylinder; C is a mixture of combustion products; $T^{\prime}$ is the thermal field created during fuel combustion; $\mathrm{M}$ is the mechanical field created during fuel combustion; D - cylinder-piston group of a diesel engine; G - main generator; V - vehicle speed; B3 - exhaust gases; B'3 - part of the exhaust gases supplied for recirculation; Bx -whirling effect of waste gases; B'2 - additional air supplied from the atmosphere through the recirculation system to the diesel suction system.

For further increasing the efficiency of the recirculation system, the author carried out special studies of the effect of an electrostatic field on the combustion of a rotating flame.

The tests carried out showed that the combustion process in a rotating flame is concentrated in the central part of the flame, which increases as the flow rate increases. In this case, the application of a positive potential to the rotating rotor, and a negative potential to the body, intensifies the combustion process.

The effect can be explained by the fact that negatively charged ions will appear in the volume of a neutral environment due to a whirl when molecules collide with an internal negatively charged surface, which will accumulate in the volume of the combustion chamber and contribute to the intensification of the combustion process. These results were used to improve the design of the recirculation system.

\section{Practical suggestions}

On the basis of the technical contradiction resolution (TC-2) according to the above su-field form of self-regulation to ensure in all modes of adjusting the amount of exhaust gases supplied to recirculation, depending on the engine load with a minimum metal consumption and maximum reliability of the device, the author has developed a device for recirculation of exhaust gases, which is shown in fig. 2. [1]. 

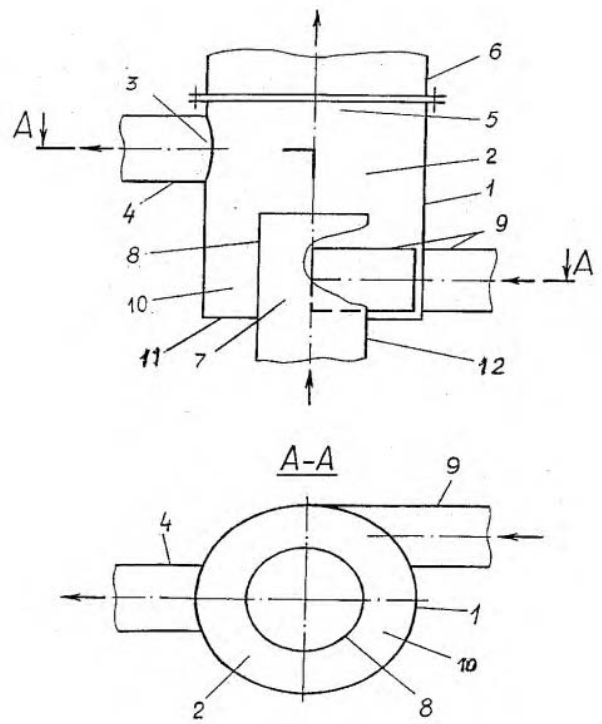

Fig.2. Self-regulated recirculation system.

The device works in the following way Exhaust gases from the exhaust manifold flow through the pipeline 9 tangentially to the inner surface of the whirl chamber 2 into the cavity 10 formed by the inner surface of the whirl chamber 2 , the outer surface of the outlet section 8 of the pipe 7 and the end wall 11 connecting these surfaces. In this case, due to the tangentially directed supply, the exhaust gases move in the cavity 10 in the form of a whirl (in a spiral form) flow, in the central zone of which a vacuum is created, which ensures the ejection of air from the pipe 7 into the cavity of the whirl chamber 2.

Since the ejected air is colder and correspondingly heavier than the exhaust gases, it partially moves to the inner wall of the whirl chamber 2 due to the centrifugal forces generated by the whirl flow of the exhaust gases. This movement of the air flow is accompanied by its interaction with the whirl flow of the exhaust gases, during which the ejected air is heated and humidified. Besides air, heavy (including soot microparticles) components of exhaust gases are also carried to the periphery of the whirl flow due to the action of centrifugal forces, which, together with humidified air, are discharged from the upper part of cavity 2 through hole 5 into exhaust pipe 6, and from the middle part of the whirl flow, the light components of the exhaust gases, together with the heated sucked in air, will be supplied for recirculation through hole 3 into the intake manifold 4. Moreover, the higher the speed of the exhaust gas whirl is, the greater the air flow due to ejection and the air content in the recirculated flow will be, i.e. the amount of recirculated exhaust gas will be automatically adjusted due to the engine load.

Besides that, the installation of inlet end 12 of air inlet 7 in the direction of movement of the vehicle on which has the engine, will increase the amount of supplied air from the speed of movement due to the counter flow. As a result, the process of adjusting the amount of recirculated exhaust gases depending on the engine load and driving speed will intensify, and the efficiency of the engine operation when driving at significant speeds will increase by enhancing the air supplied to the engine combustion chamber. 
Thus, controlled exhaust gas recirculation is carried out with their direct interaction in a whirling flow with air supplied by ejection and counterflow, which will help to reduce the concentration of harmful nitrogen oxides in the exhaust gases leaving cavity 2 through the exhaust pipe 6. In this case, the whirl movement of exhaust gases continues in pipe 6, which reduces their friction against the inner walls of the latter, thereby reducing resistance and increasing efficiency.

For a gas turbine supercharged engine, a gas turbine can be used as a swirler.

The second version of the exhaust gas recirculation system with the effect of an electrostatic field, for which the patent "Method for exhaust gas recirculation and a device for its implementation" was obtained, is shown in Fig.3. [15]. in view 1 - longitudinal section of the device; in view 2- section A-A in view 1.

This system works in the following way.

The exhaust gases through the gas pipeline 8 enter cavity 9 of the whirl tube 1 , twist around tube 6 and are directed from end partition 10 towards hole 5, forming a dense gas flow on the inner surface of whirl tube 1 . In this case, a vacuum is formed in the central part of the whirling flow, due to which air is sucked in from the atmosphere, which mixes with a part of the exhaust gases to form a cooled flow, which is supplied for recirculation through pipe 3 to inlet manifold 4.

As a result, the contents of the exhaust gases in the whirling flow will change due to the change in the effect of the centrifugal force field: at high speeds, heavy components will be located at the periphery, and light components in the center; at low speeds, such separation does not occur, and heavy components squeeze out the light ones to the periphery. Thus, at high and medium loads in the central part of the whirling flow, mainly water vapor will be concentrated, while the greater the speed of the whirl of the exhaust gases, the greater the air flow due to ejection and the more water vapor in the central part of the whirl, so the quantity and quality of recirculated gases will be automatically adjusted depending on the engine load. Inlet 11 of pipe 6 is directed towards the movement of the vehicle, which will increase the amount of supplied air from the speed of movement due to the oncoming flow. As a result, the process of adjusting the quantity and quality of recirculated gases will be enhanced, depending on the engine load and speed, and the efficiency of the engine will increase by enlarging the air supplied to the combustion chamber.

A swirler 12 is installed in pipe 6 on insulator 13, to which positive charge 15 of energy source 14 is supplied, and negative charge 16 is connected to the body of pipe 6 . As a result, negatively charged ions will appear, which will contribute to the intensification of the combustion process.

\section{Conclusion}

The self-regulated exhaust gas recirculation system developed by the author in order to reduce harmful emissions and increase efficiency can be used in diesel engines used in various fields of activity.

The use of electrostatic action in recirculation systems makes it possible to enhance the synergistic effect of a comprehensive reduction of harmful emissions and fuel consumption.

The developed recirculation system can also be used in other heat and power plants for various purposes. 


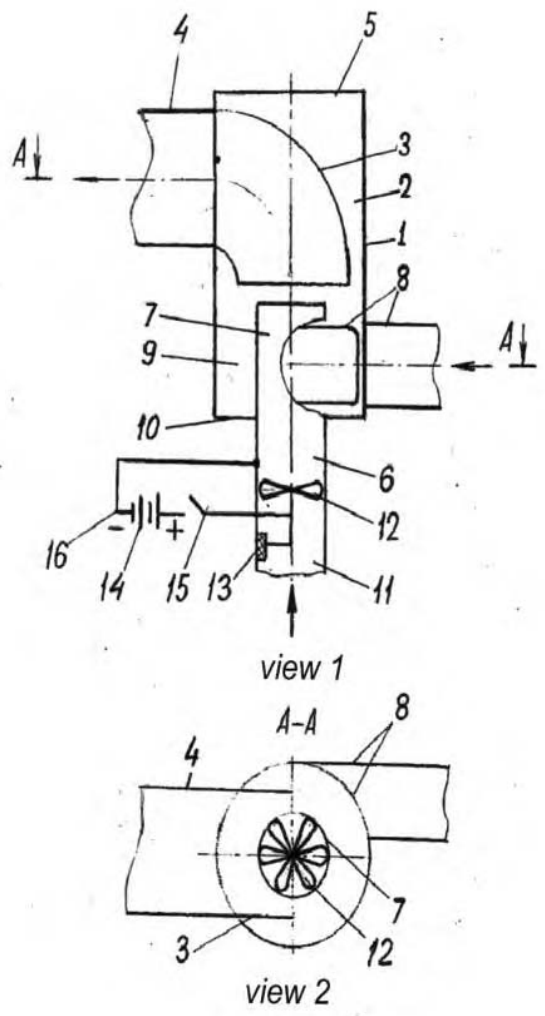

Fig.3. Electrostatic Exhaust Gas Recirculation

\section{References}

1. I. Ivanov, Improving the efficiency of transport power plants. Monography, 65-77 (2010)

2. G, Kuharenok, V. Berezan, Road transport, 42, 5-11 (2018)

3. G, Kuharenok, V. Berezan, Science and technology, 1, 57-63 (2014)

4. V. Vedruchenko, V. Krainov, E. Lazarev, P. Litvinov, Omsk Scientific Bulletin. Series Devices, machines and technologies, 6(150), 68-72 (2016)

5. E. Lazarev, A. Pomaz, A. Salov, Bulletin of the South Ural State University. Series Mechanical Engineering,132-136 (2013)

6. A. Ukhanov, D. Ukhanov, I. Adgamov, magazine: Niva Volga region. Publisher: Penza State Agrarian University, 1(34), 66-71 (2015)

7. United States Patent no. 10,634,101, issued on April 28, was assigned to MAGNETI MARELLI S.p.A. (Corbetta, Italy). "Exhaust gas recirculation valve actuator device (EGR) in an internal combustion engine and related exhaust gas recirculation valve assembly" was invented by Giancarlo Bartolotta (Corbetta, Italy), Stefano Domma (Corbetta, Italy), Matteo Avanzi (Corbetta, Italy) and Stefano Musolesi (Corbetta, Italy).The patent was filed on June 26, 2017, under Application 15/632, 975 http://patft.uspto.gov/netacgi/nph-

Parser?Sect $1=$ PTO $2 \&$ Sect $2=$ HITOFF $\& p=1 \& u=\% 2$ Fnetahtm $1 \% 2$ FPTO $\% 2$ Fsearch - 
bool.html\&r $=1 \& \mathrm{f}=\mathrm{G} \& \mathrm{l}=50 \& \mathrm{co} 1=\mathrm{AND} \& \mathrm{~d}=\mathrm{PTXT} \& \mathrm{~s} 1=10634101 \& \mathrm{OS}=10634101 \& \mathrm{R}$ $\underline{\mathrm{S}=10634101}$ (Last accessed 21.05.2020)

8. United States Patent no. 10,480,432, issued on Nov. 19, was assigned to CONTINENTAL AUTOMOTIVE GMBH (Hannover, Germany)."Exhaust gas recirculation valves for a forced-induction internal combustion engine with exhaust gas recirculation" was invented by Hong Zhang (Tegernheim, Germany). The patent was filed on Aug. 10, 2015, under Application 15/507, 451 http://patft.uspto.gov/netacgi/nph-

Parser?Sect $1=$ PTO $2 \&$ Sect $2=$ HITOFF $\& p=1 \& \mathrm{u}=\% 2$ Fnetahtml $\% 2$ FPTO $\% 2$ Fsearchbool.html\&r $=1 \& \mathrm{f}=\mathrm{G} \& \mathrm{l}=50 \& \mathrm{co} 1=\mathrm{AND} \& \mathrm{~d}=\mathrm{PTXT} \& \mathrm{~s} 1=10480432 \& \mathrm{OS}=10480432 \& \mathrm{R}$ $\underline{\mathrm{S}=10480432}$ (Last accessed 21.05.2020)

9. United States Patent no. 10,288,014, issued on May 14, was assigned to Ford Global Technologies LLC (Dearborn, Mich.)."Internal combustion engine with exhaust-gas recirculation arrangement and method for operating an internal combustion engine of said type" was invented by Ford Global Technologies, LLC (Dearborn, Mich.).The patent was filed on Sept. 29, 2017, under Application 15/721, $587 \mathrm{http}: / /$ patft.uspto.gov/netacgi/nph-

Parser?Sect $1=$ PTO $2 \&$ Sect $2=$ HITOFF $\& p=1 \& u=\% 2$ Fnetahtml $\% 2 F P T O \% 2 F$ searchbool.html\& $\mathrm{r}=1 \& \mathrm{f}=\mathrm{G} \& \mathrm{l}=50 \& \mathrm{co} 1=\mathrm{AND} \& \mathrm{~d}=\mathrm{PTXT} \& \mathrm{~s} 1=10288014 \& \mathrm{OS}=10288014 \& \mathrm{R}$ $\mathrm{S}=10288014$ (Last accessed 21.05.2020)

10. United States Patent no. 10,215,086, issued on Feb. 26, was assigned to FEV Europe $\mathrm{GmbH}$ (Aachen, Germany)."Exhaust gas recirculation system for an internal combustion engine and method for operating such an exhaust gas recirculation system" was invented by FEV GMBH (Aachen, Germany). The patent was filed on June 16, 2015, under Application 15/325, 578 http://patft.uspto.gov/netacgi/nphParser?Sect $1=$ PTO $2 \&$ Sect $2=$ HITOFF $\& p=1 \& u=\% 2$ Fnetahtml $\% 2 F P T O \% 2 F$ search bool.html\&r=1\&f=G\&l=50\&co1=AND\&d=PTXT\&s $1=10215086 \& O S=10215086 \& \mathrm{R}$ $\mathrm{S}=10215086$ (Last accessed 21.05.2020)

11. United States Patent no. 9,903,319, issued on Feb. 27, was assigned to GM GLOBAL TECHNOLOGY OPERATIONS LLC (Detroit)."Internal combustion engine with internal exhaust gas recirculation flow control with variable exhaust rebreathing" was invented by GM Global Technology Operations LLC (Detroit).The patent was filed on Jan. 21, 2016, under Application 15/003, $245 \mathrm{http} / /$ patft.uspto.gov/netacgi/nphParser? $\backslash$ (Last accessed 27.05.2020)

12. United States Patent no. 9,574,526, issued on Feb. 21, was assigned to NISSAN MOTOR Co. LTD. (Yokohama-shi, Japan)."Exhaust gas recirculation control device and exhaust gas recirculation control method for internal combustion engine" was invented by NISSAN MOTOR CO., LTD. (Yokohama-shi, Kanagawa, Japan). The patent was filed on Dec. 24, 2013, under Application 14/763, 933 http://patft.uspto.gov/netacgi/nph-Parser (Last accessed 27.05.2020)

13. M. Meerovich, L. Shragina, Technology of creative thinking, 298-316 (2016)

14. I. Ivanov, G. Persiyanova, Collection of articles of the 8th international conference. scientifically.- practic.al. Interagromash, 592-596 (2015)

15. I. Ivanov, Patent R.F№ 2410560 (2011) 